\section{Influence of Spray Application Technique on Spray Deposition in Greenhouse Ivy Pot Plants Grown on Hanging Shelves}

\author{
Pascal Braekman and Dieter Foqué \\ Institute for Agricultural and Fisheries Research (ILVO), Technology \& \\ Food Science Unit, Agricultural Engineering, Burg. Van Gansberghelaan \\ 115, bus 1, 9820 Merelbeke, Belgium

\section{Marie-Christine Van Labeke \\ Ghent University, Faculty Bioscience Engineering, Department of Plant Production, Coupure Links 653, 9000 Ghent, Belgium}

\section{Jan G. Pieters}

Ghent University, Faculty Bioscience Engineering, Department of Biosystems Engineering, Coupure Links 653, 9000 Ghent, Belgium

\section{David Nuyttens ${ }^{1}$ \\ Institute for Agricultural and Fisheries Research (ILVO), Technology \& Food Science Unit, Agricultural Engineering, Burg. Van Gansberghelaan 115, bus 1, 9820 Merelbeke, Belgium}

Additional index words. Hedera algeriensis cv. Montgomery, spray nozzle, spray gun, vertical spray boom, application rate, plant protection

\begin{abstract}
As a result of the decreasing availability of authorized plant protection products, adequate pest control becomes more difficult in many ornamental crops and almost no information is available about the optimization of spray application techniques in ornamental crops. Yet, spray boom systems - instead of the still predominantly used spray guns - might improve crop protection management in greenhouses considerably. Application rate, nozzle type, and configuration will influence the spray deposition and, as such, its efficiency. In this study, spray deposition in ivy pot plants [Hedera algeriensis cv. Montgomery, Hibb.], grown on hanging shelves in greenhouses, was compared with a traditional spray gun with a disc-core nozzle and a manually pulled trolley equipped with two vertical spray booms. The sprayings with the spray gun were performed at an application rate of $8500 \mathrm{~L} \cdot \mathrm{ha}^{-1}$. For the vertical spray boom system, two different reduced application rates $\left(2500\right.$ and $\left.5000 \mathrm{~L} \cdot \mathrm{ha}^{-1}\right)$ with five different combinations of nozzle type, size, and pressure for each application rate were investigated. This research underlined that, besides the application rate, also the spray application equipment used has an important effect on the spray depositions. Nozzle type, size, and pressure on the vertical spray boom system only had a minor effect on the spray deposition. Although the spray gun performed well on the easily accessible crop zone with the runners, its performance in the more dense main crop zone was inferior. With $240 \%$ more sprayed liquid $\left(8500 \mathrm{~L} \cdot \mathrm{ha}^{-1}\right)$ and chemicals, the realized depositions in this crop zone were not significantly different from the ones obtained with the vertical spray boom system applying only $2500 \mathrm{~L} \cdot \mathrm{ha}^{-1}$. Spraying at $5000 \mathrm{~L} \cdot \mathrm{ha}^{-1}$, the vertical spray boom system achieved a $82.9 \%$ higher overall spray deposition in the main crop canopy zone compared with the spray gun at an application rate of $8500 \mathrm{~L} \cdot \mathrm{ha}^{-1}$. For the sprays applied with the vertical spray boom system, doubling the application rate resulted in equally higher spray depositions, except for the inner canopy deposition for which higher application rates were more effective.
\end{abstract}

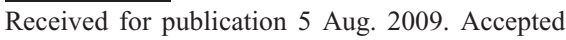
for publication 8 Sept. 2009.

We acknowledge the Flemish Government-IWT Vlaanderen for financial support. We also thank the "Research Center for Ornamental Plants (PCS)," the local grower, and the technicians for supplying equipment, greenhouses, and technical support.

${ }^{1}$ To whom reprint requests should be addressed; e-mail david.nuyttens@ilvo.vlaanderen.be.
}

Although ornamental plants occupy only $12 \%$ of the horticultural plant production (fruits, ornamentals, and vegetables) surface in Flanders (Belgium), their output $(0.46$ billion euro) represents not less than $34 \%$ of the total horticultural production value. Greenhouses take $\approx 4.3 \%$ of the horticultural production surface for their account; 33\% (714 ha) of this surface is used to produce ornamental plants (Flemish Government,
2006). Goossens et al. (2004) showed that $90 \%$ of the growers still use high-pressure spray equipment (i.e., spray guns or lances) to apply plant protection products, although spray boom equipment is becoming increasingly popular. A survey carried out in 2007 among growers of ornamental plants confirms this and furthermore reveals that almost all growers are convinced that high application rates and spray pressures are indispensable to obtain a satisfactory coverage and sufficient penetration of the often dense crop canopies. This survey also revealed that the present-day spray application techniques are insufficient and need to be improved (Braekman and Sonck, 2008). Previous studies already demonstrated that the use of (vertical) spray booms improves spray distribution (Nuyttens et al., 2004a) and reduces labor costs and operator exposure (Nuyttens et al., 2004b, 2009a). For similar reasons, research into automatic spraying of plant protection products has been addressed by several authors like González et al. (2009), Moltó et al. (2000), and Subramanian et al. (2005). Despite these important advantages, many questions remain concerning the optimal settings for (automated) spray boom equipment (Braekman and Sonck, 2007).

It is generally accepted that the foliar application of a pesticide to a crop is an inefficient process with only a fraction of the pesticide actually being retained on plants and some being lost to the ground (Balan et al., 2008; Salyani et al., 2007). This loss of pesticides to the ground is even more pronounced in the case of spraying potted plants grown on hanging shelves using a spray gun or lance. The amount retained on the crop depends on many factors, including the formulation of the pesticide (Gossen et al., 2008; $\mathrm{Yu}$ et al., 2009), the volume of spray applied (Gauvrit and Lamrani, 2008; Medina et al., 2005; Pergher and Gubiani, 1995), the type of spray equipment (Braekman et al., 2009; Ebert et al., 2004) and its operation (Halley et al., 2008), the weather conditions (Balan et al., 2008; Nuyttens et al., 2007a) and the droplet size spectrum (Abdelbagi and Adams, 1987; Nuyttens et al., 2007b, 2009b).

Until now, very few studies have been carried out to improve the spray application techniques used in ornamental crops. A study of Gilles (1992) showed that an electrostatic reduced-volume application of permethrin insecticide to greenhouse-grown chrysanthemums resulted in significantly higher spray deposition compared with the conventional high-volume application. However, this technique also resulted in significantly higher contamination of nontarget surfaces of the greenhouse bench tops and aisle ways. Derksen et al. (2008) concluded that when spraying a poinsettia canopy with a single-nozzle handgun sprayer, the variability in deposition across the treatment area is a continuing problem. Based on two experiments, Zhu et al. (2008) demonstrated that an increase of the application rate when spraying nursery trees could greatly increase spray deposition but did not greatly increase spray coverage on 
targets inside canopies. Literature describing research results on optimal spray application techniques for fruits and vegetables grown in greenhouses also offers interesting related information. Tanigawa et al. (1993) reported an inadequate deposit of fungicide on the lower leaf surface of several strawberry cultivars for control of powdery mildew when swinging a nozzle pendulously over the crop. Nuyttens et al. (2004a) demonstrated that reducing the vertical nozzle spacing from 0.50 to $0.35 \mathrm{~m}$ when spraying with vertical spray booms was a simple and cheap adaptation to obtain a much better spray distribution in tomatoes as well as in peppers. Bjugstad and Sønsteby (2004) underlined the importance of spray equipment when spraying an outdoor strawberry crop. Multiple $80^{\circ}$ flat fan nozzles at a distance of $200 \mathrm{~mm}$ from the plant proved to be the best solution for practical use. For smaller and larger plants, three ISO 03 nozzles and five ISO 05 nozzles achieved the highest deposition and coverage, respectively. Braekman et al. (2009) found that a vertical spray boom performed better than the reference spray equipment in strawberries (spray gun) and in tomatoes (air-assisted sprayer) and that nozzle type and settings significantly affected spray deposition and crop penetration.

Besides the traditional fixed or rolling benches on the floor, Flemish growers of potted plants frequently use hanging shelves (Braekman and Sonck, 2008). Depending on the type of greenhouse structure, one or more of these shelves are positioned at 2 to $4 \mathrm{~m}$ height in the greenhouse arches. In this way, growers try to make maximal use of the available heated greenhouse space. In almost all cases, the shelves are used to store either plants at an early growth stage or mother stock plants. The actual height and width of the shelves varies from company to company or even within a company. Because these shelves are located above the traditional benches, closely situated to the roof infrastructure of the greenhouse, the only currently available and useful equipment to apply plant protection products to the plants stored on the shelves are spray guns. In most cases, the spray gun is operated from the ground floor and thus, the spray cloud has to be targeted from quite some distance and from below toward the crop canopies.

In Belgium, almost all plant protection products authorized for the treatment of greenhouse ornamental plants express the dose as a concentration (e.g., $50 \mathrm{~g} / 100 \mathrm{~L}$ spray volume) (Fytoweb, 2008) that is different from the more commonly used dose rate/ha (Meynecke, 2004). It is up to the growers to decide themselves the actual volume rate and thus also the quantity of plant protection product applied on a certain surface. It is believed that growers base these decisions on crop properties (e.g., growth stage, plant and canopy density, leaf properties) and pest occurrence (e.g., intensity and site of infestation) to determine the optimal application rate to treat a specific crop. Unfortunately, in practice, the majority of the growers do not bother to do this exercise for each treatment and just spray until runoff. Because the definition of the starting point of runoff is a rather personal matter, very divergent quantities of spray liquid are used when a number of growers are individually asked to spray a given crop until runoff (Bjugstad and Hermansen, 2008). Moreover, information on labels usually provides little guidance on application techniques other than advising the operator to provide good coverage (Derksen et al., 2008). To simulate this situation, the presented experiment included three different application rates all with the same tracer concentrations.

The main objective of this research was to investigate the effect of spray application technique on the spray deposition in ivy pot plants grown on hanging shelves in green- houses. In particular, the effect of application rate, nozzle type, size and spray pressure, and the difference between the traditional spray gun and a vertical spray boom system was investigated.

\section{Materials and Methods}

Plant material and configuration. The experiment was conducted in a commercial greenhouse used for ivy production in January and Feb. 2008 and the treated cultivar was Hedera algeriensis cv. Montgomery (Hibb.). Ivy motherstock plants were produced on hanging shelves at a height of $2.80 \mathrm{~m}$ and the treated shelf was situated straight above a concrete aisle (Fig. 1). The shelf was attached to the roof infrastructure of the greenhouse by iron chains, had a width of

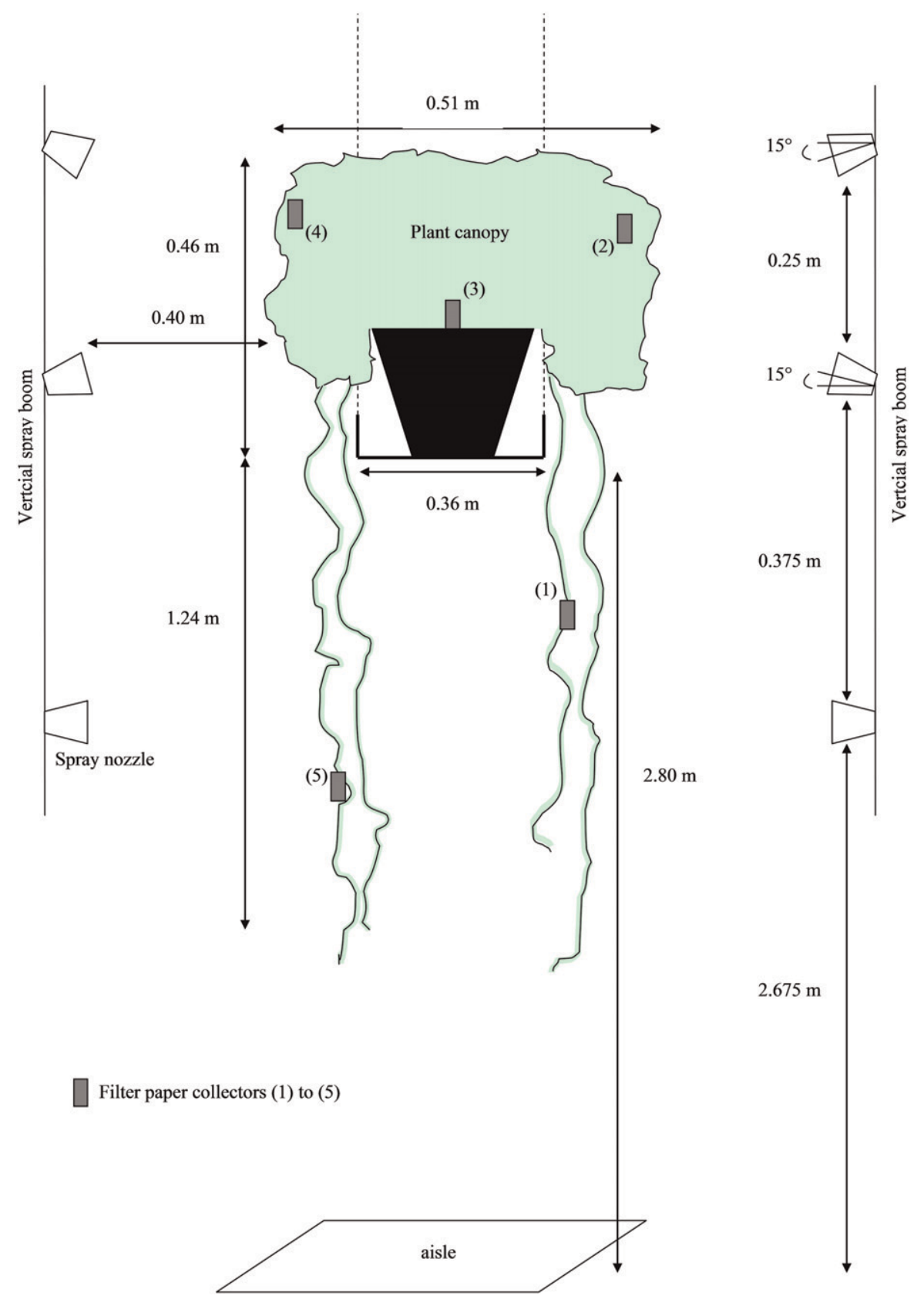

Fig. 1. Positions of filter papers within the ivy canopy and setting of vertical spray boom system. 
$0.36 \mathrm{~m}$, and was equipped with raised edges with a height of $0.05 \mathrm{~m}$. Plastic polyvinyl chloride pots with a height of $0.21 \mathrm{~m}$ and a diameter of $0.23 \mathrm{~m}$, each containing three plants, were put on a shelf at an average distance of $\approx 0.50 \mathrm{~m}$. The ivy canopy had an average height of $0.46 \mathrm{~m}$, measured from the bottom of the shelf to the top of the plants, and an average width of $0.51 \mathrm{~m}$. Runners for cutting production were more or less uniformly distributed on both sides of the shelf and had an average length of $1.24 \mathrm{~m}$. The growth stage could be described as "fully grown" main canopy and regrowth on the runners was just appearing 7 to $10 \mathrm{~d}$ after cuttings were taken.

Spray equipment. Two different spray application systems were tested: a spray gun equipped with a disc-core nozzle (reference) and vertical spray booms mounted on a trolley. Actual application rate and other spray application parameters (spray equipment, nozzle type and size, spray pressure, and traveling speed) for the 11 different treatments are presented in Table 1.

The spray gun (TeeJet Technologies, Wheaton, IL) was fed by a 100-m long hose (diameter $3 / 4$ inch). During the experiments, the hose was half unrolled from the drum. Because no pressure gauge was present on the spray gun itself, pressure was set on the gauge mounted on the pump. The cropspecific spray application parameters for the trials with the spray gun were based on the grower's experience and corresponded with a theoretical application rate of $8500 \mathrm{~L} \cdot \mathrm{ha}^{-1}$. Actual traveling speed was $0.95 \mathrm{~km} \cdot \mathrm{h}^{-1}$ corresponding with an application rate of $8438 \mathrm{~L} \cdot \mathrm{ha}^{-1}$.

For the 10 applications with the vertical spray booms on a manually pulled trolley (Fig. 1), five different nozzle types or sizes were evaluated for two theoretical application rates of 2500 and $5000 \mathrm{~L} \cdot \mathrm{ha}^{-1}$ at a theoretical traveling speed of $2.4 \mathrm{~km} \cdot \mathrm{h}^{-1}$. Nozzle types included Albuz ATR hollow cone nozzles (Saint-Gobain Solcera, Evreux cedex, France), Albuz AVI-Twin air-inclusion twin fluid nozzles (Saint-Gobain Solcera), Agrotop air-inclusion flat fan nozzles (Agrotop, GmbH, Obertraubling, Germany), and TeeJet XR extended-range flat fan nozzles (TeeJet Technologies). During the experiments, the actual travel speeds and spray pressures were measured to calculate the actual application rate (Table 1). The average spray distance with the vertical spray boom system was $0.40 \mathrm{~m}$, measured between the orifice of the middle nozzle and the crop contours.

Crop-specific parameters were included in the nozzle configuration of the vertical spray boom system because foliage density was much lower for the runners than for the main crop canopy. Two sets of three nozzles of the same type were installed on the booms at a reduced nozzle spacing of 0.250 or $0.375 \mathrm{~m}$ and with an offset angle of $7^{\circ}$ as suggested by Nuyttens et al. (2004a) and presented in Figure 1. The nozzle heights above the aisle were $2.675,3.050$, and $3.300 \mathrm{~m}$. The lowest nozzle was orientated directly toward the crop canopy, whereas the middle and top nozzle were slightly inclined $\left(15^{\circ}\right)$, respectively, upward and downward, toward the main crop canopy. Within a given configuration, the ISO nozzle size of the lowest nozzles was half of the size of the nozzles used for the middle and top positions. This choice was substantiated by visual evaluation of the spray patterns on water-sensitive papers. Strips of this water-sensitive paper were put on the contours of the canopy and the uniformity of the spray liquid distribution for a given nozzle configuration (size and orientation) was visually evaluated.

Experimental setup. Two well-separated parts of the hanging shelf were randomly selected for sampling. Where both parts were sprayed with the spray gun at the same application rate $\left(\approx 8500 \mathrm{~L} \cdot \mathrm{ha}^{-1}\right)$, for the vertical spray boom system, the first part was treated at $\approx 2500 \mathrm{~L} \cdot \mathrm{ha}^{-1}$, whereas the second part was sprayed at $\approx 5000 \mathrm{~L} \cdot \mathrm{ha}^{-1}$. For the different sprayings, the same collectors were used at the same locations but with a different mineral chelate (Table 1). In this way, a good comparison among the different spray systems and selected nozzle settings (nozzle type and size, spray pressure) was possible. Between two successive sprayings, there was enough time to allow the crop and the collectors to dry completely. In both selected shelf parts, five nonconsecutive plants were chosen as repetitions. In each sampled plant, five artificial collectors were placed in the crop canopies at five different places as illustrated in Figure 1. Schleicher \&
Schuell filter papers $(7.5 \mathrm{~cm}$ by $2.65 \mathrm{~cm}$, type 2589 D; Novolab N.V., Geraardsbergen, Belgium) were used as collectors. Two sampling points were situated on the runners and three sampling points were located on the main crop canopy (Fig. 1). Of the three latter sampling points, two were situated at the crop contours and one inside the crop canopy. For sample points one, two, four, and five, the collectors were alternately attached on top or at the bottom of the leaves. In total, 50 collector samples with six mineral chelates were analyzed corresponding with 300 deposition measurements. With this setup, the depositions measured on the main crop canopy contours (sample points 2 and 4) and on the runners (sample points 1 and 5) gave a good appreciation of the spray liquid distribution, whereas the depositions measured on the inner collector (sample point 3 ) can be used to evaluate crop penetration.

Mineral chelates as tracer. Spray deposition and distribution were evaluated quantitatively using mineral chelates as tracers on filter paper collectors (De Moor et al., 2002; Langenakens et al., 2002; Nuyttens et al., 2004a, 2004b, 2009a). These products perform similarly as pesticides under the same conditions. Iron, cobalt $(\mathrm{Co})$, copper $(\mathrm{Cu})$, manganese $(\mathrm{Mn})$, molybdenum, and zinc (Zn) chelates (BMS Micro-Nutrients NV, Bornem, Belgium) were used to quantify spray deposition. For each spray application technique, a different mineral chelate was used (Table 1). The targeted concentrations of each chelate solution in the tank was 1.0 $\mathrm{g} \cdot \mathrm{L}^{-1}$. This methodology was used before in a satisfactory way by Nuyttens et al. (2004a) to evaluate the influence of different spray boom settings on the spray deposition in tomato and pepper crops grown in greenhouses. Cross et al. (2001a, 2001b, 2003) used mineral chelates as a tracer to evaluate the effect of spray liquid flow rate, spray quality, and air volumetric rate on the spray deposition and losses from an axial fan orchard sprayer in different-sized apple trees. These mineral chelates are normally used as horticultural leaf fertilizers; hence, their use in normal concentrations does not damage the crop. Inductively coupled plasma (ICP) analysis (VISTA-PRO; Varian, Palo Alto, CA) was used to determine metal concentrations on the filter paper collectors after

Table 1. Spray application parameters for the 11 different trials

\begin{tabular}{|c|c|c|c|c|c|c|c|c|}
\hline \multirow[b]{2}{*}{ Spray equipment } & \multirow{2}{*}{$\begin{array}{l}\text { Theoretical } \\
\text { application } \\
\text { rate }\left(\mathrm{L} \cdot \mathrm{ha}^{-1}\right)\end{array}$} & \multicolumn{3}{|c|}{ Nozzle type and size } & \multirow{2}{*}{$\begin{array}{c}\text { Traveling } \\
\text { speed }\left(\mathrm{km} \cdot \mathrm{h}^{-1}\right)\end{array}$} & \multirow{2}{*}{$\begin{array}{c}\text { Spray } \\
\text { pressure } \\
(\mathrm{kPa})\end{array}$} & \multirow{2}{*}{$\begin{array}{c}\text { Actual } \\
\text { application } \\
\text { rate }\left(\mathrm{L} \cdot \mathrm{ha}^{-1}\right)\end{array}$} & \multirow{2}{*}{$\begin{array}{l}\text { Mineral } \\
\text { chelate }\end{array}$} \\
\hline & & Manufacturer & Plant zone 1 & Plant zone 2 & & & & \\
\hline \multirow[t]{10}{*}{ Vertical boom } & 2500 & Albuz & ATR orange & ATR brown & 2.51 & 500 & 2310 & Manganese \\
\hline & & Albuz & AVI-Twin 11002 & AVI-Twin 11001 & 2.79 & 500 & 2175 & Molybdenum \\
\hline & & Agrotop & TD 11002 & TD 11001 & 2.09 & 500 & 2902 & Copper \\
\hline & & TeeJet & XR 11003 & XR 110015 & 2.82 & 200 & 2003 & Zinc \\
\hline & & TeeJet & XR 11002 & XR 11001 & 2.32 & 500 & 2575 & Iron \\
\hline & 5000 & Albuz & ATR gray & ATR orange & 2.63 & 500 & 3570 & Manganese \\
\hline & & Albuz & AVI-Twin 11004 & AVI-Twin 11002 & 2.95 & 500 & 4129 & Molybdenum \\
\hline & & Agrotop & TD 11004 & TD 11002 & 2.03 & 500 & 5981 & Copper \\
\hline & & TeeJet & XR 11006 & XR 11003 & 2.38 & 200 & 4793 & Zinc \\
\hline & & TeeJet & XR 11004 & XR 11002 & 2.24 & 500 & 5363 & Iron \\
\hline Spray gun & 8500 & TeeJet & D8 & 45 & 0.95 & $1000^{z}$ & 8438 & Cobalt \\
\hline
\end{tabular}

zPressure at the pump. 
extraction with $0.16 \mathrm{M}$ nitric acid $\left(\mathrm{HNO}_{3}\right)$ (66+\%, p.a.; Acros Organics, Geel, Belgium). Earlier experiments indicated that there was no interference among the minerals $\mathrm{Co}, \mathrm{Cu}$, $\mathrm{Mn}$, and $\mathrm{Zn}$ with the ICP analysis. The detection limits in nitric acid for $\mathrm{Co}, \mathrm{Cu}, \mathrm{Mn}$, and $\mathrm{Zn}$ were very low $(5,3,10$, and $10 \mathrm{ppb}$, respectively) (De Moor et al., 2002). Furthermore, mineral chelates are stable and a high recovery can be achieved for each of them (Murray et al., 2000).

Based on the concentration measurements of the actual chelate solution in the tank, the calculation of the actual application rate (Table 1), and the analysis of the blank samples (i.e., collectors not exposed to any chelate solution), the concentrations of the minerals measured on each collector were normalized to a concentration of $1.0 \mathrm{~g} \cdot \mathrm{L}^{-1}$ in the tank and an application rate of 2500 , 5000 , or $8500 \mathrm{~L} \cdot \mathrm{ha}^{-1}$ according to the used spray technique (Table 1). Following this approach, spray deposition is defined as the amount of mineral chelate per unit of crop area $\left(\mu \mathrm{g} \cdot \mathrm{cm}^{-2}\right)$ at a constant mineral tank concentration.

Statistical analysis. The normalized concentrations on each collector were transformed by a common (base 10) logarithm transformation before statistical analysis. Factorial analysis of variance (ANOVA) was used to study the effect of the application rate $(\mathrm{V})$, the nozzle type $(\mathrm{N})$, and the collector position $(\mathrm{P})$. This analysis was done for the spray depositions on the runners (sample 1 and 5) and for the spray depositions on the main crop canopy (sample points 2,3 , and 4 ) separately. Because the interaction terms $\mathrm{V}^{*} \mathrm{~N}$ and $\mathrm{P}^{*} \mathrm{~N}$ were never significant $(P>$ 0.05 ), the analysis to evaluate the effect of the nozzle type in both crop zones was reduced to a main effects ANOVA. For the deposition on the runners, the term $\mathrm{P} * \mathrm{~V}$ also showed no significant interaction and hence, for this crop zone, the analysis to evaluate the effect of these two parameters was also reduced to a main ANOVA. Contrary to this, for the main crop canopy, the interaction term $\mathrm{P} * \mathrm{~V}$ was significant $(P<0.05)$. A factorial
ANOVA was performed to evaluate the effects of the application rate and collector position in this crop zone. In both approaches, significant differences were assessed by Tukey's post hoc test. A $P$ value $<0.05$ was considered to be statistically significant. All analyses were done in Statistica 8.0 (Statsoft Inc., Tulsa, OK).

\section{Results and Discussion}

Figures 2 through 5 present the measured spray depositions as absolute values $\left(\mu \mathrm{g} \cdot \mathrm{cm}^{-1}\right)$. A lot of the box plots presented in these figures show considerable spread, indicating an important variation of the measured spray deposition.

Influence of the sample points. The location of the sample points (depth in canopy, upper or underside of leaf) and the position of the collectors (orientation with respect to spray cloud, shielding of leaves or stems, exposure to runoff) affected the spray deposition (Fig. 2A-B). The spray depositions on the runners (sample points 1 and 5) were not significantly influenced by the location of the sample points (Fig. 2A). For the main crop zone (sample points 2, 3, and 4), a significant interaction between the collector position and the application rate was found (Fig. 2B).

Sample point 3, situated deeply inside the main canopy, yielded significantly lower spray depositions for the application rates of 2500 and $8500 \mathrm{~L} \cdot \mathrm{ha}^{-1}$ compared with sample points 2 and 4, indicating inferior crop penetration. For these application rates, depositions on sample points 2 and 4 showed no significant differences. For the application of $5000 \mathrm{~L} \cdot \mathrm{ha}^{-1}$, there was no significant difference among the three sampling positions in the main crop zone.

Effect of spray system and application rate. Spray system as well as application rate clearly influenced absolute spray deposition. Figures $2 \mathrm{~B}$ and 3 summarize the effect of these parameters on the measured depositions for the main crop zone and the crop zone comprising the runners, respectively.
It should be clearly stated that for all sprayings, the same tracer concentrations were used. Compliance with the current plant protection practices in Flemish greenhouses justifies this choice. Although not quantitatively assessed, during the experiments, one could visually state that the degree of runoff, especially on the runners, was rather low with the vertical spray boom system applying $2500 \mathrm{~L} \cdot \mathrm{ha}^{-1}$ but was substantial for this system when spraying $5000 \mathrm{~L} \cdot \mathrm{ha}^{-1}$ and also for the spray gun at $8500 \mathrm{~L} \cdot \mathrm{ha}^{-1}$. In general, the recovered quantities of applied spray liquid were rather low. For the two application rates $\left(2500\right.$ and $\left.5000 \mathrm{~L} \cdot \mathrm{ha}^{-1}\right)$ applied with the vertical spray boom system, an average crop deposition recovery of $\approx 20 \%$ of the applied volume was found, whereas only on average $14.2 \%$ of the chemicals applied with the spray gun $\left(8500 \mathrm{~L} \cdot \mathrm{ha}^{-1}\right)$ was recovered from the crop canopy. In this approach, the measured crop deposition recovery was expressed as relative values (\%) compared with the maximal feasible spray deposition assuming a perfectly uniform distribution of the spray liquid on the contours of the crop canopy.

Evaluating the deposition results for the two crop zones reveals that the spray gun performed quite well on the runners (Fig. 3 ).With this technique, the spray liquid was targeted from below to the easily accessible runners, which might explain the higher spray deposition on this part of the crop. For the sprays performed with the spray boom system, a significant difference was found between the lower and higher application rate. Because the concentration of tracer was the same for both application rates, doubling the application rate justifies the increase in spray depositions.

On the main crop canopy, the spray gun performed a lot worse (Fig. 2B). At an application rate of $8500 \mathrm{~L} \cdot \mathrm{ha}^{-1}$, the overall spray deposition achieved with the spray gun in this crop zone was only $17 \%$ higher than the spray deposition obtained when using the vertical spray boom system at an application rate of $2500 \mathrm{~L} \cdot \mathrm{ha}^{-1}$, although $240 \%$ more
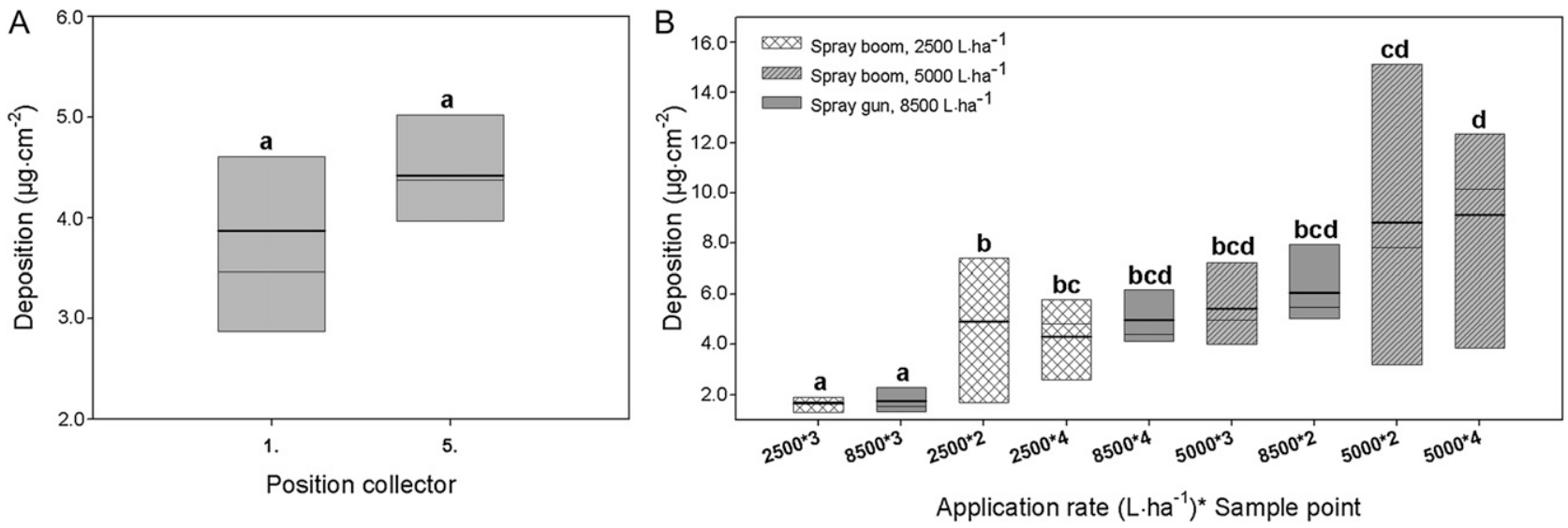

Fig. 2. Spray deposition $\left(\mu \mathrm{g} \cdot \mathrm{cm}^{-2}\right)$ on (A) the runners depending on collector position and (B) the main crop canopy zone depending on the application rate*collector position. Box plots with a common letter are not significantly different (Tukey multiple comparison, $P<0.05$ ). Box plots present nonoutlier range $(25 \%$ to $75 \%$ range), mean $(-)$, and median $(-)$. 


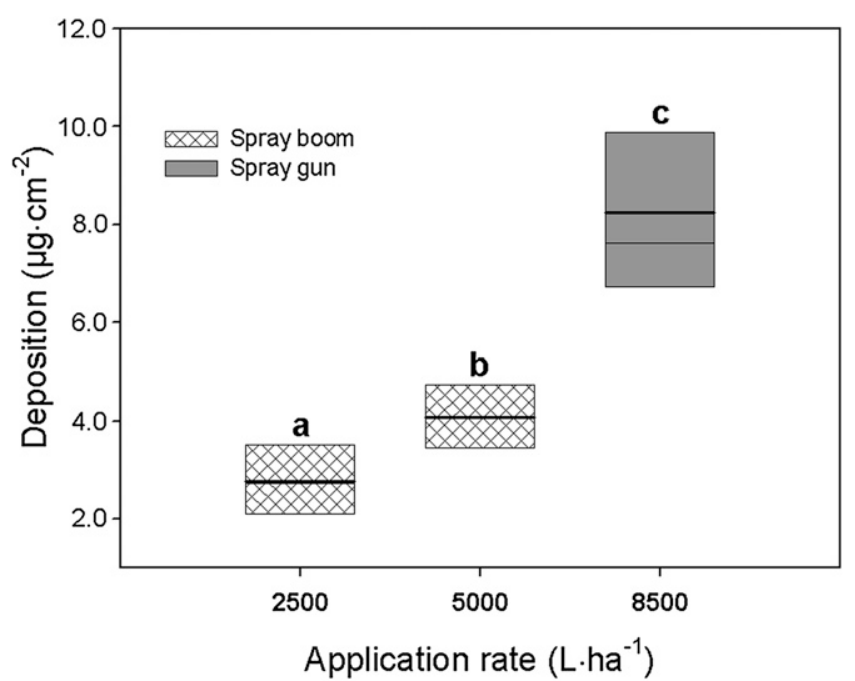

Fig. 3. Spray deposition $\left(\mu \mathrm{g} \cdot \mathrm{cm}^{-2}\right)$ on the runners depending on the application rate. Box plots with a common letter are not significantly different (Tukey multiple comparison, $P<0.05$ ). Box plots present nonoutlier range ( $25 \%$ to $75 \%$ range), mean (-), and median (-).

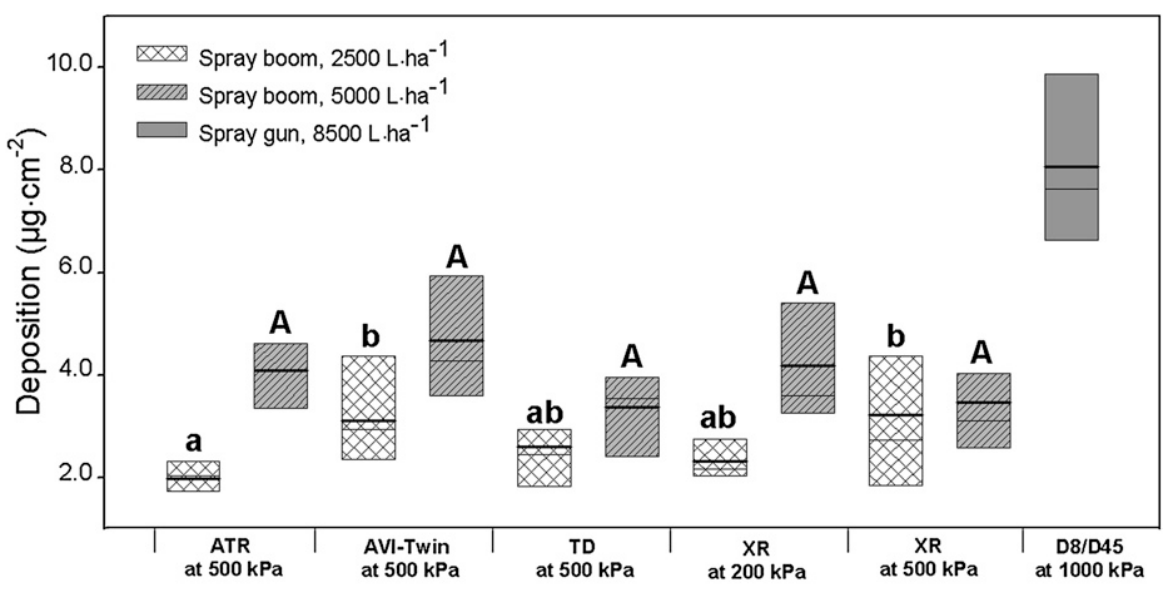

Nozzle type

Fig. 4. Spray deposition $\left(\mu \mathrm{g} \cdot \mathrm{cm}^{-2}\right)$ on the runners depending on nozzle type and configuration. Box plots with a common letter (grouped in uppercase, $2500 \mathrm{~L} \cdot \mathrm{ha}^{-1}$ and lowercase, $2500 \mathrm{~L} \cdot \mathrm{ha} \mathrm{a}^{-1}$ ) are not significantly different (Tukey multiple comparison, $P<0.05)$. Box plots present nonoutlier range $(25 \%$ to $75 \%$ range), mean (-), and median (-).

tracer was applied with the spray gun. Compared with the deposition measured for the vertical spray boom system spraying at 5000 $\mathrm{L} \cdot \mathrm{ha}^{-1}$, the difference is also pronounced. In this case, with $30 \%$ less spray applied, the spray boom system achieves an almost $83 \%$ higher average spray deposition for the main crop canopy. The inferior performance of the spray gun in this crop zone can mainly be attributed to the very low deposition measured on sampling point 3 (Fig. 2B) situated deeply in the main canopy at the base of the plants (Fig. 1). The spray deposition measured on this place for the spray gun was only $32 \%$ compared with the spray boom system applying $5000 \mathrm{~L} \cdot \mathrm{ha}^{-1}$, whereas a $30 \%$ higher application rate was used. The smaller accessibility of the main crop canopy and the fact that the spray cloud has to travel a longer distance to reach the crop canopy may ex- plain the lower spray deposition obtained for the spray gun. Moreover, the gutter of the hanging shelf constitutes an important obstacle for the spray cloud targeted from below. In these conditions, it is practically impossible to achieve a uniform liquid distribution across the crop canopy. This kind of cropping system also hampers the deposition of sufficient amounts of spray liquid inside the canopy. Not surprisingly, most of the companies with hanging shelves report having major problems in suppressing pests and diseases occurring in the crops on these shelves.

In accordance with spray deposition on the runners, doubling the application rate for the vertical spray boom system generally led to a proportional rise of the average spray deposition in the main crop zone, although this effect was not observed for the spray depositions registered for sample point 3 . At this position, doubling the application rate with the spray boom system resulted in an increase of the spray deposition of $228 \%$. Besides the direct effect of the higher application rate, the higher deposition inside the main crop canopy was probably also stimulated by runoff. After all, ivy leaves have a considerable, deep-lying main vein that constitutes a kind of gutter. Along these veins, an important part of the occurring runoff is conducted to the leaf base and from there on it flows off through the stems to the base of the plant, where sample point 3 was situated (Fig. 1).

Biological efficacy trials, carried out as a part of the Belgian authorization procedures for the approval of plant protection products, are usually based on an application rate of $1000 \mathrm{~L} \cdot \mathrm{ha}^{-1}$ ground surface. For this experiment, much higher application rates for the alternative spray boom system were selected based on common horticultural practice. Moreover, the chosen application rates (2500 and $5000 \mathrm{~L} \cdot \mathrm{ha}^{-1}$ ) represent already a considerable reduction ( $71 \%$ and $41 \%$, respectively) compared with the application rate used by the grower $\left(8500 \mathrm{~L} \cdot \mathrm{ha}^{-1}\right) . \mathrm{Al}$ though also in ornamental plant production, application rates are nearly always expressed with respect to the ground surface, it is more logical to take the actual sprayed crop surface into account, certainly when a vertical spray boom system is used. In this perspective, application rates of 2500 and $5000 \mathrm{~L} \cdot \mathrm{ha}^{-1}$ ground surface corresponded with application rates of, respectively, 1565 and 3135 $\mathrm{L} \cdot \mathrm{ha}^{-1}$ crop surface. So, the lower application rates proposed in these experiments using a vertical spray boom system as an alternative application technique are still quite high compared with those used when spraying arable crops (25 to $200 \mathrm{~L} \cdot \mathrm{ha}^{-1}$ ) (Butler Ellis and Scotford, 2003), fruit (50 to $500 \mathrm{~L} \cdot \mathrm{ha}^{-1}$ ) (Cross et al., 2001a), or outdoor grown vegetables $\left(150\right.$ to $\left.400 \mathrm{~L} \cdot \mathrm{ha}^{-1}\right)$ (Jensen and Nielsen, 2008; Piché et al., 2000).

Effect of nozzle type and setting. Figures 4 and 5 show the spray depositions measured for the different nozzle types and settings for the runners and the main crop canopy, respectively. No significant differences were found among the different nozzle types for the main crop, whereas the hollow cone nozzle (ATR) resulted in significantly lower deposition on the runners spraying at 2500 $\mathrm{L} \cdot \mathrm{ha}^{-1}$. To complete, also the deposition results for the disc-core nozzle mounted on the spray gun are shown. As described before, the spray system and the amount of application rate were more important factors with regard to spray deposition.

Two combinations of sizes of an extended range flat fan nozzle (XR) were used (Table $1)$. The combination with the bigger sizes were used within their recommended pressure range at $200 \mathrm{kPa}$, but the combination with the smaller size was used at a pressure $500 \mathrm{kPa}$, which is well above its recommended pressure range. This choice allowed to verify the influence of the pressure at which 


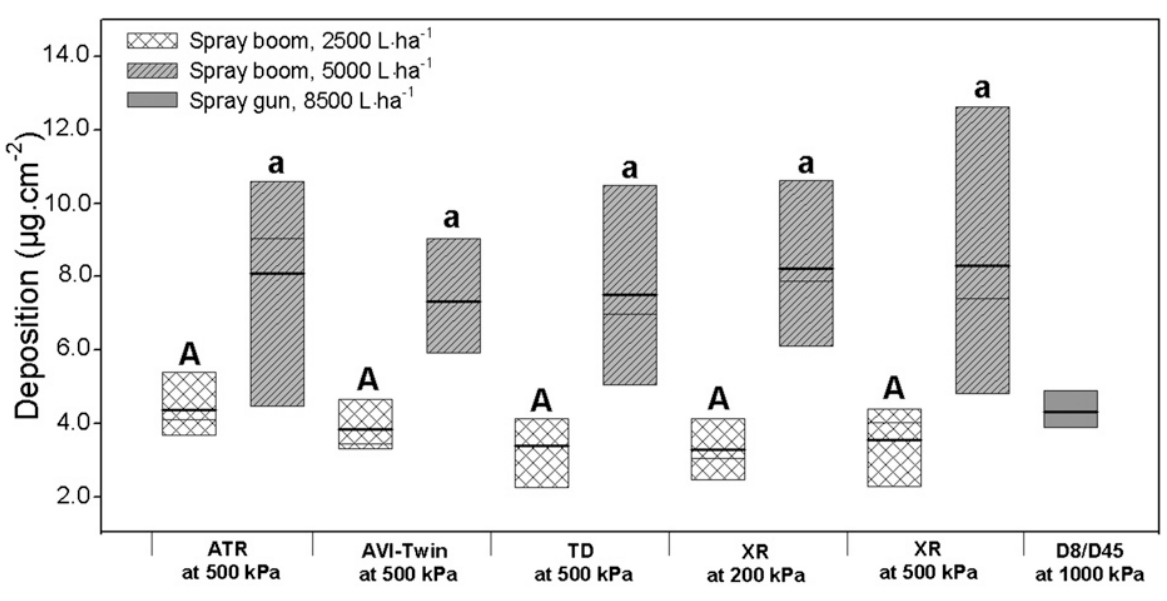

Nozzle type

Fig. 5. Spray deposition $\left(\mu \mathrm{g} \cdot \mathrm{cm}^{-2}\right)$ on the main crop canopy zone depending on nozzle type and configuration. Box plots with a common letter (grouped in uppercase, $2500 \mathrm{~L} \cdot \mathrm{ha}^{-1}$ and lowercase, 2500 $\mathrm{L} \cdot \mathrm{ha}^{-1}$ ) are not significantly different (Tukey multiple comparison, $P<0.05$ ). Box plot presents nonoutlier range ( $25 \%$ to $75 \%$ range), mean $(-)$, and median $(-)$.

a certain nozzle type is used on the achieved spray deposition. Similar research performed in strawberries (Braekman et al., 2009) showed that using small-sized extended-range flat fan nozzles at a pressure above the recommended pressure range resulted in a significantly lower deposition, especially at the inside of the strawberry canopy when spraying at an application rate of $1000 \mathrm{~L} \cdot \mathrm{ha}^{-1}$. However, in this experiment, no significant differences could be found between these two nozzle settings for either of the two application rates.

\section{Conclusions}

This experiment underlines that, besides the application rate, the spray application equipment is an important factor defining the spray deposition achieved when spraying ivy pot plants stored on hanging shelves in greenhouses.

Although the spray gun, operated from the ground floor, still performed best on the easily accessible crop zone with the runners, its performance in the more dense main crop canopy zone was inferior. With $240 \%$ more spray liquid $\left(8500 \mathrm{~L} \cdot \mathrm{ha}^{-1}\right)$ and chemicals, the realized deposition on these plant parts was not significantly different from the ones obtained with the vertical spray boom system applying only $2500 \mathrm{~L} \cdot \mathrm{ha}^{-1}$. Spraying at 5000 $\mathrm{L} \cdot \mathrm{ha}^{-1}$, the vertical spray boom system achieved a $82.9 \%$ higher overall spray deposition in the main crop canopy than the one registered using the spray gun at an application rate of $8500 \mathrm{~L} \cdot \mathrm{ha}^{-1}$.

For the sprays applied with the vertical spray boom system, increasing the application rate (from 2500 to $5000 \mathrm{~L} \cdot \mathrm{ha}^{-1}$ ) resulted in equally higher spray depositions, except for the inner canopy deposition for which higher application rates were able to yield proportionally higher spray depositions. Furthermore, the results from the tests with the vertical spray boom system suggest that at such high application rates, the effect of nozzle type, size, and pressure is of minor importance regarding the achieved spray depositions at a constant application rate.

\section{Literature Cited}

Abdelbagi, H.A. and A.J. Adams. 1987. Influence of droplet size, air-assistance, and electrostatic charge upon the distribution of ultra-low-volume sprays on tomatoes. Crop Prot. 6:226-233.

Balan, M.G., O.J.G. Abi-Saab, C.G. da Silva, and A. do Rio. 2008. Deposition of the spraying suspension for three spray nozzles under different meteorological conditions. SeminaCiencias Agrarias 29:293-298.

Bjugstad, N. and P. Hermansen. 2008. Control of spraying equipment in practical use in greenhouses in Norway. Asp. Appl. Biol. 84:171177.

Bjugstad, N. and A. Sønsteby. 2004. Improved spraying equipment for strawberries. Asp. Appl. Biol. 71:335-342.

Braekman, P., D. Foqué, W. Messens, M.-C. Van Labeke, J.G. Pieters, and D. Nuyttens. 2009. Effect of spray application technique on spray deposition in greenhouse strawberries and tomatoes. Pest Mgt. Sci. doi. 10.1002/ps.1858.

Braekman, P. and B. Sonck. 2007. An appropriate technical inspection methodology to tackle the great diversity of spray equipment used in Flemish greenhouses. Asp. Appl. Biol. 83:95-98.

Braekman, P. and B. Sonck. 2008. A review of the current spray application techniques in various ornamental plant productions in Flanders, Belgium. Asp. Appl. Biol. 84:303-308.

Butler Ellis, M.C. and I.M. Scotford. 2003. The deposit characteristics of pesticide sprays applied at low volumes. Proc. BCPC Int.Congress Crop Sci. Technol. 279-284.

Cross, J.V., P.J. Walklate, R.A. Murray, and G.M. Richardson. 2001a. Spray deposits and losses in different sized apple trees from an axial fan orchard sprayer: 1. Effects of spray liquid flow rate. Crop Prot. 20:13-30.

Cross, J.V., P.J. Walklate, R.A. Murray, and G.M. Richardson. 2001b. Spray deposits and losses in different sized apple trees from an axial fan orchard sprayer: 2. Effects of spray quality. Crop Prot. 20:333-343.

Cross, J.V., P.J. Walklate, R.A. Murray, and G.M. Richardson. 2003. Spray deposits and losses in different sized apple trees from an axial fan orchard sprayer: 3. Effects of air volumetric flow rate. Crop Prot. 22:381-394.

De Moor, A., G. Vergauwe, and J. Langenakens. 2002. Evaluation of chemical analysis of minerals for the assessment of spray deposits. Asp. Appl. Biol. 66:409-420.

Derksen, R.C., J. Frantz, C.M. Ranger, J.C. Locke, H. Zhu, and C.R. Krause. 2008. Comparing greenhouse handgun delivery to pointsettias by spray volume and quality. Trans. ASABE 50:27-33.

Ebert, T.A., R.C. Derksen, R.A. Downer, and C.R. Krause. 2004. Comparing greenhouse sprayers: The dose-transfer process. Pest Manag. Sci. 60:507-513.

Flemish Government. 2006. Agricultural report 2005.

Fytoweb. 2008. Consultation of authorized products. 19 Nov. 2008. <http://www.fytoweb.be>

Gauvrit, C. and T. Lamrani. 2008. Influence of application volume on the efficacy of clodinafoppropargyl and fenoxaprop-P-ethyl on oats. Weed Res. 48:78-84.

Gilles, D.K. 1992. Foliar and non-target deposition from conventional and reduced-volume pesticide application in greenhouses. J. Agr. Food Chem. 40:2510-2516.

González, R., F. Rodríguez, J. Sánchez-Hermosilla, and J.G. Donaire. 2009. Navigation techniques for mobile robots in greenhouses. Appl. Eng. Agr. 25:153-165.

Gossen, B.D., G. Peng, T.M. Wolf, and M.R. McDonald. 2008. Improving spray retention to enhance the efficacy of foliar-applied disease and pest-management products in field and crop rows. Can. J. Plant Pathol. 30:505-516.

Goossens, E., S. Windey, and B. Sonck. 2004. Information service and voluntary testing of spray guns and other types of sprayers in horticulture. Asp. Appl. Biol. 71:41-48.

Halley, S., G. Van Ee, V. Hofman, S. Panigrahi, and H. Gu. 2008. Fungicide deposition measurement by spray volume, drop size, and sprayer system in cereal grains. Appl. Eng. Agric. 24:15-21.

Jensen, P.K. and B.J. Nielsen. 2008. Influence of volume rate and nozzle angling on control of potato late blight with flat fan, pre-orifice and air induction nozzles. Asp. Appl. Biol. 84:447452.

Langenakens, J., G. Vergauwe, and A. De Moor. 2002. Comparing hand-held spray guns and spray booms in lettuce crops in a greenhouse. Asp. Appl. Biol. 66:123-128.

Medina, R., J. Sánchez-Hermosilla, F. Agüera, and J.C. Gazquez. 2005. Deposition analysis of several application volumes of pesticides adapted to the growth of a greenhouse tomato crop. Acta Hort. 691:179-185.

Moltó, E., B. Martín, and A. Gutiérrez. 2000 Pesticide loss reduction by automatic adaptation of spraying on globular trees. J. Agr. Eng. Res. 78:35-41.

Meynecke, J.O. 2004. Evaluation and authorisation of plant protection products within the European Union. J Appl. Bot. Food Qual. 78:157160.

Murray, R., J. Cross, and S. Ribout. 2000. The measurement of multiple spray deposits by sequential application of metal chelate tracer. Ann. Appl. Biol. 137:245-255.

Nuyttens, D., P. Braekman, S. Windey, and B. Sonck. 2009a. Potential dermal pesticide exposure affected by greenhouse spray application technique. Pest Manag. Sci. 65:781-790.

Nuyttens, D., M. De Schampheleire, P. Verboven, E. Brusselman, and D. Dekeyser. 2009b. Droplet 
size-velocity characteristics of agricultural sprays. Trans. ASABE 52:1471-1480.

Nuyttens, D., M. De Schampheleire, K. Baetens, and B. Sonck. 2007a. The influence of operator controlled variables on spray drift from field crop sprayers. Trans. ASABE 50:11291140.

Nuyttens, D., K. Baetens, M. De Schampheleire, and B. Sonck. 2007b. Effect of nozzle type, size and pressure on spray droplet characteristics. Biosystems Eng. 97:333-345.

Nuyttens, D., S. Windey, and B. Sonck. 2004a. Optimisation of a vertical boom for greenhouse spray applications. Biosystems Eng. 89:417423.

Nuyttens, D., S. Windey, and B. Sonck. 2004b. Comparison of operator exposure for five different greenhouse spraying applications. J. Agr. Saf. Health 10:187-195.

Pergher, G. and R. Gubiani. 1995. The effect of spray application rate and airflow on foliar deposition in a hedgerow vineyard. J. Agr. Eng. Res. 61:205-216.

Piché, M., B. Panneton, and R. Thériault. 2000. Field evaluation of air-assisted boom spraying on broccoli and potato. Trans. ASABE 43:793-799.

Salyani, M., M. Farooq, and R.D. Sweeb. 2007. Spray deposition and mass balance in citrus orchard applications. Trans. ASABE 50:19631969.

Subramanian, V., T.F. Burks, and S. Singh. 2005. Autonomous greenhouse sprayer vehicle using machine vision and ladar for steering control. Appl. Eng. Agr. 21:935-943.
Tanigawa, M., T. Nakano, T. Hagihara, K. Okayanma, and S. Sezaki. 1993. Relationship between the control effect of fungicides on powdery mildew (Sphaerotheca humuli) and their deposits on strawberry (Fragaria ananassa) leaves. J. Pestic. Sci. 18:135-140.

Yu, Y., H. Zhu, H.E. Ozkan, R.C. Derksen, and C.R. Krause. 2009. Evaporation and deposition coverage area of droplets containing insecticides and spray additives on hydrophilic, hydrophobic, and crabapple leaf surfaces. Trans. ASABE 52:39-49.

Zhu, H., R.H. Zondag, R.C. Derksen, M. Reding, and C.R. Krause. 2008. Influence of spray volume on spray deposition and coverage within nursery trees. J. Environ. Hort. 26: $51-57$. 